Research Article

\title{
Optimization and Experimental Study of an Intelligent Bamboo-Splitting Machine Charging Manipulator
}

\author{
Tian-Hu Liu (D, Yong-Lu Wen, Gui-Qi Li, and Xiang-Ning Nie \\ College of Engineering, South China Agricultural University, Guangzhou 510642, China \\ Correspondence should be addressed to Tian-Hu Liu; liuparalake@126.com
}

Received 8 January 2020; Accepted 17 February 2020; Published 17 March 2020

Academic Editor: L. Fortuna

Copyright (c) 2020 Tian-Hu Liu et al. This is an open access article distributed under the Creative Commons Attribution License, which permits unrestricted use, distribution, and reproduction in any medium, provided the original work is properly cited.

\begin{abstract}
A nonautomatic bamboo-splitting machine must charge with material and change tools manually. However, manual charging is very dangerous. An intelligent bamboo-splitting machine can feed automatically and change tools intelligently and has broad application prospects. A charging manipulator is an important part of an intelligent bamboo-splitting machine. The size of the manipulator was optimized here using a genetic algorithm. The capture rate, centering rate, and dynamic characteristics of an intelligent bamboo-splitting machine charging manipulator, in which key factors were considered, were experimentally studied. First, three different manipulators, with arm lengths at 210,220, and $230 \mathrm{~mm}$, were developed. Then, the bamboo materials were divided into three gradients $(60-85,85-110$, and 110-135 $\mathrm{mm}$ ) according to diameter ranges. Accelerators were used to measure the manipulator arm dynamic characteristics, and a high-speed charge-coupled device was used to record the grasping process. Experimental results showed that the manipulator capture rate with an arm length of $=220 \mathrm{~mm}$ was as high as $100 \%$, but that of manipulators with arm lengths of $=210$ and $230 \mathrm{~mm}$ was 96 and $98.67 \%$, respectively. Thus, the manipulator with a $220 \mathrm{~mm}$ arm length showed better performance than the other two manipulators. Trend curves of the influence of material diameter on capture time were similar to an exponential function.
\end{abstract}

\section{Introduction}

Asia Pacific, America, and Africa are the main distribution areas of bamboo in the world [1]. In Asia, bamboo plants are mainly distributed in China, India, and other developing countries. Bamboo grows rapidly and has good mechanical properties, such that it can be processed into many kinds of daily necessities. The production process of bamboo products is shown in Figure 1. Bamboo material is split into pieces by a bamboo-splitting machine. Then, it is drawn into a silk from by a wire-drawing machine, dried, and finally processed into products, such as toothpicks and chopsticks. Thus, a bamboo-splitting machine plays an important role in bamboo processing. A nonautomatic bamboo-splitting machine must charge with material and change tools manually. However, manual charging is very dangerous. An intelligent bamboo-splitting machine can feed and charge automatically and can change tools reliably and therefore has broad application prospects. A charging manipulator is an important part of an intelligent bamboo-splitting machine.

As an important part in many kinds of intelligent machinery, many studies have been conducted regarding various manipulators, such as a flexible manipulator [2,3]. Peng et al. have studied an apple internal-quality-grading manipulator [4]. Li et al. have designed a kind of transplanting manipulator [5]. Wan et al. have carried out dimensional synthesis of a parallel manipulator using a particle swarm optimization algorithm [6]. A reconfigurable 6-degree-of-freedom (DOF) manipulator has been optimized [7], in which three performance criteria have been combined using the weighted-sum approach and optimization was carried out using the sequential simplex method. Mandur and Budman have discussed a method for updating mechanism model parameters using state measurements $[8,9]$. Okazaki et al. have developed a 6-DOF manipulator driven by McKibben artificial muscles [10]. A P-4R (prismatic-four-rotational-joint) has been proposed to measure a 


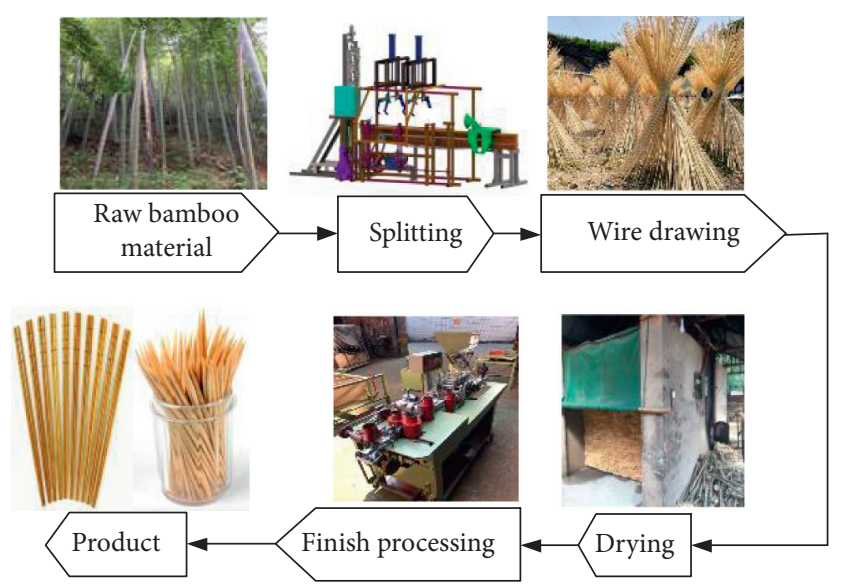

Figure 1: The production process for bamboo products.

high-temperature steel cylinder robotic system [11]. Abe has built a dynamic model for a planar flexible-rigid manipulator by assumed mode method (AMM) [12]. Abe defined trajectories as cubic splines and used particle swarm optimization (PSO) to optimize the spline control points. Trajectory functions have been defined as high order polynomials for planar flexible manipulators [13]. A 7-DOF manipulator has been designed, actuated entirely by antagonistic McKibben artificial muscle pairs [14]. Ahmad et al. have proposed a PD-type fuzzy logic controller for tip angular position control in a flexible joint manipulator [15]. Nikdel et al. have also developed a fuzzy approach based on the parallel distributed compensation technique in controlling a flexible joint robot [16].

A genetic algorithm, analytical approach, and linearleast-square (LLS) method are widely used in mechanism design. For example, $\mathrm{Li}$ and $\mathrm{Xu}$ have used a genetic algorithm to optimize a planar 3-DOF parallel manipulator [17]. Gao et al. have applied a genetic algorithm based on the Pareto front approach to synthetize a 6-DOF parallel manipulator [18]. A genetic algorithm has also been adopted to optimize the parameters of cubic polynomials, in which four cubic polynomials are used to describe angular velocities of a flexible manipulator's two joints [19]. Chen et al. have proposed an analytical approach to determine the redundant parameters for the calibration of serial manipulators [20]. A manipulator has been studied using an electrostatic model [21]. An approach to consider the bearing's contribution to the manipulator dynamics has been introduced [22]. Liu et al. studied an elliptical boundary model method detecting object for intelligent machinery $[23,24]$. Bucolo et al. studied control methods of imperfect dynamical systems $[25,26]$.

The complex characteristics of bamboo-splitting processes make it expensive to devise an accurate mechanism. An empirical model in which a certain degree of expertise is required is somewhat easier and more suitable for mechanism design. In this paper, the charging manipulator of an intelligent bamboo-splitting machine was optimized using a genetic algorithm, and a series of experiments was conducted to study key performance characteristics, such as capture rate, centering rate, and dynamic characteristics.

\section{Design and Optimization of Manipulator}

2.1. Composition of an Intelligent Bamboo-Splitting Machine. In general, an intelligent bamboo-splitting machine includes a feeding mechanism, charging manipulator, tool changer, and control mechanism (Figure 2). A local structure of an intelligent bamboo-splitting machine was developed for this study, where (1) is the charging manipulator, (2) represents the feeding mechanism, (3) represents the frame, (4) represents the pushing mechanism, and (5) represents the automatic tool changer (Figure 3). The feeding mechanism (2) fed bamboo materials and concurrently measured diameters automatically and continuously, the charging manipulator (1) grasped material accurately, the pushing mechanism (5) pushed materials continuously to the tool, and the automatic tool changer (5) changed tools automatically according to material diameter.

The workflow chart of this intelligent bamboo-splitting machine is shown in Figure 4. During operation, the tool was first reset. During feeding, the bamboo diameter was measured using a laser beam sensor. The machine then selected the tool automatically according to the measured diameter. At the end of the feeding process, the bamboo arrived at the tray and was picked up by the charging manipulator, grasped, and centered. Then, it was pushed into the tool by the pushing mechanism.

2.2. Manipulator Design and Optimization. The manipulator structure has a great influence on its stability and motion performance, and thus it was necessary to obtain the ideal motion performance through optimization. In the process of optimization, the working space of the manipulator needed to be maximized, but its flexibility and stability needed to satisfy the working requirements.

Two optional structures of the manipulator are shown in Figures 5(a) and 5(b). As the sizes of big and small arms are the same, the workspace of these two manipulators is drawn together with the solid lines in Figure 5(c) representing the manipulator of Figure 5(a), and the dotted line represents that of Figure 5(b) after movement. It was obvious that, under the condition of the arm and joints sizes being the same, the target trajectory of the mechanism shown in Figure 5(a) was larger than that in Figure 5(b). Therefore, the charging manipulator in Figure 5(a) was adopted.

The manipulator in the configuration grasped the target object through an up and down movement of a pneumatic cylinder and rotations of the shoulder, elbow, and wrist joints. Due to the limitation of the overall size of the intelligent bamboo-splitting machine, the working path of the manipulator fingers must meet formula (1) to grasp the target object.

$$
f(x)_{1 \min }=a+b \sin \theta_{1}+d \sin \theta_{2}>600,
$$

where $a, b, c, \theta_{1}$, and $\theta_{2}$ are shown in Figure 6.

To make the manipulator reach the maximum target trajectory with minimized size, the objective function is written as 




FIGURE 2: Overall structure of intelligent bamboo-splitting machine.

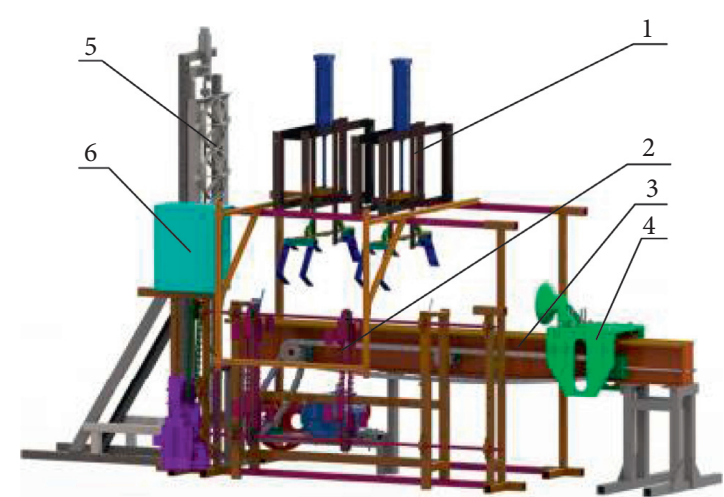

(a)

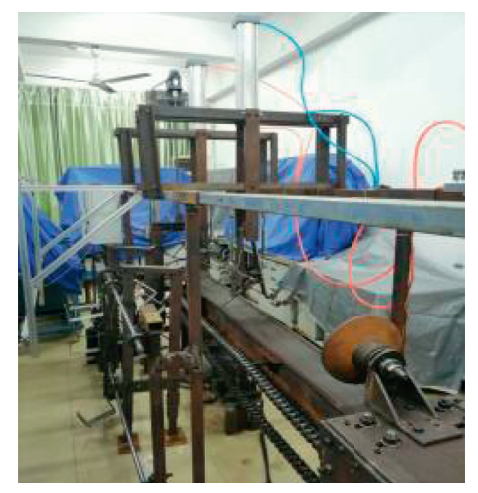

(b)

Figure 3: (a) The virtual model and (b) the image of developed bamboo-splitting machine.

$$
\text { Minimize } f(x)_{2}=a+b+c+d .
$$

The optimization function must be subject to formula (1) to reduce the manipulator weight and ensure that the manipulator is lighter and more flexible. The ranges of $a, b, c$, $d, \theta_{1}$, and $\theta_{2}$ were from 0 to $300 \mathrm{~mm}, 0$ to $400 \mathrm{~mm}, 0$ to $500 \mathrm{~mm}, 0$ to $300 \mathrm{~mm}, 0$ to $\pi / 2$, and 0 to $3 \pi / 4$, respectively. This size optimization problem was solved using a multivariable genetic algorithm, and the algorithm flow is shown in Figure 7. A set of initial values satisfying the conditions was selected to start the optimization process. The initial population number was set as 50, the maximum evolution generation was set as 100 , the crossover probability was set at 0.7 , the mutation probability was set at 0.01 , and the termination condition was set such that the average changes of fitness function were less than $10^{-2}$.

The algorithm actually evolved 97 generations, with the optimized result of these parameters for $a, b$, and $d$ equal to 190,220 , and $220 \mathrm{~mm}$, respectively (Figure 8). The total length of rods $c$ and $d$ needed to meet $c+d \quad \sin \quad \theta_{2} \geq 600 \quad$ because $\quad 0^{\circ} \leq \theta_{2} \leq 3 \pi / 4$, $0^{\circ} \sin \quad \theta_{2} \leq 1$. Therefore, $c+d \geq 600$, when $c+d=600$, such that the object function was minimized, and the length of $\operatorname{rod} c$ was $380 \mathrm{~mm}$.
2.3. Optimized Charging Manipulator. The structure of the optimized charging manipulator is shown in Figure 9. It mainly included a cylinder (1), five hinges (10), two big arms (6), two small arms (7), two wrist joints (8), a V-shaped finger (11), and two U-shaped fingers (9). It had four columns (3), two upper beams (2), and two bottom beams (4). The cylinder (1) was mounted on upper beam (2) using bolts. Component (10) acted as a shoulder, which was mounted at the end of cylinder piston. One end of big arm (6) was connected with component (10) and another end connected with small arm (7) a through hinge. The upper end of small arm (7) was mounted on a hinge, which was also mounted on a rotation axis. V-shaped fingers (11) and U-shaped fingers (9) were mounted on the bottom end of small arm (7). In the process of charging, bamboo was picked up by U-shaped fingers (9). Next, the sample was urged to the front of the pushing mechanism before touching V-shaped fingers (11). Then, it was caught and tightly fastened between the U-shaped (9) and V-shaped fingers (11).

\section{Materials and Methods}

3.1. Materials. The test samples were bamboo of different diameters felled at the end of September 2019 at Nankun 


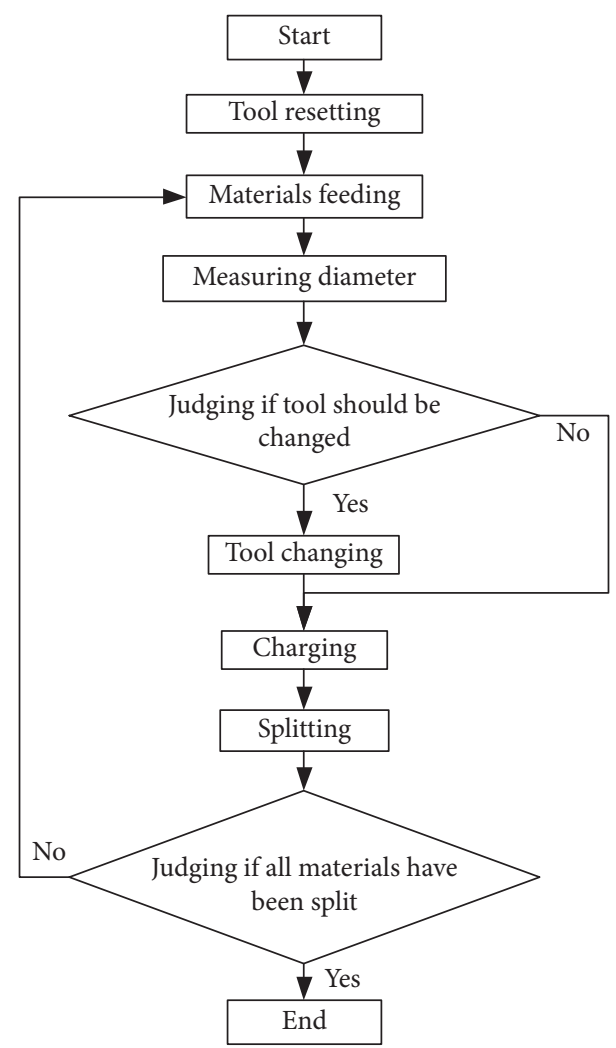

FiguRE 4: Workflow chart of intelligent bamboo-splitting machine.

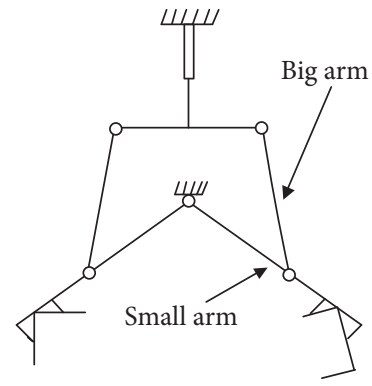

(a)

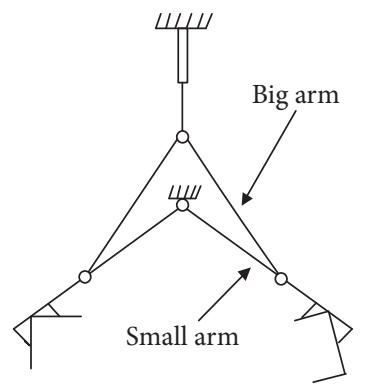

(b)

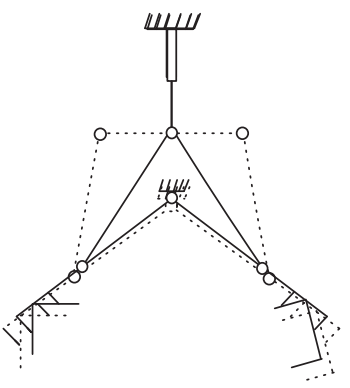

(c)

FIGURE 5: Manipulator configuration.

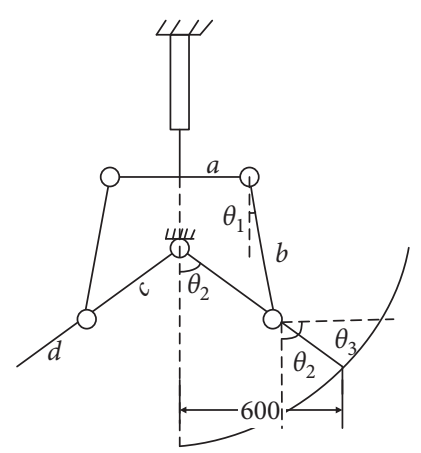

Figure 6: Manipulator parameters.
Mountain, Longmen County, Huizhou, Guangdong, China. All samples were placed at the laboratory of South China Agricultural University in Guangzhou, China, and few samples are shown in Figure 10. The sample diameters were a key parameter in this study and equal to the average of the diagonal outer diameters of both sample ends, measured using a caliper.

3.2. Methods. A previous study has demonstrated that when the length of big arm was between 200 and $240 \mathrm{~mm}$, the manipulator could grasp bamboo materials of common diameters. Therefore, three manipulators, with big arm lengths of 210,220 , and $230 \mathrm{~mm}$, were developed for this trial 


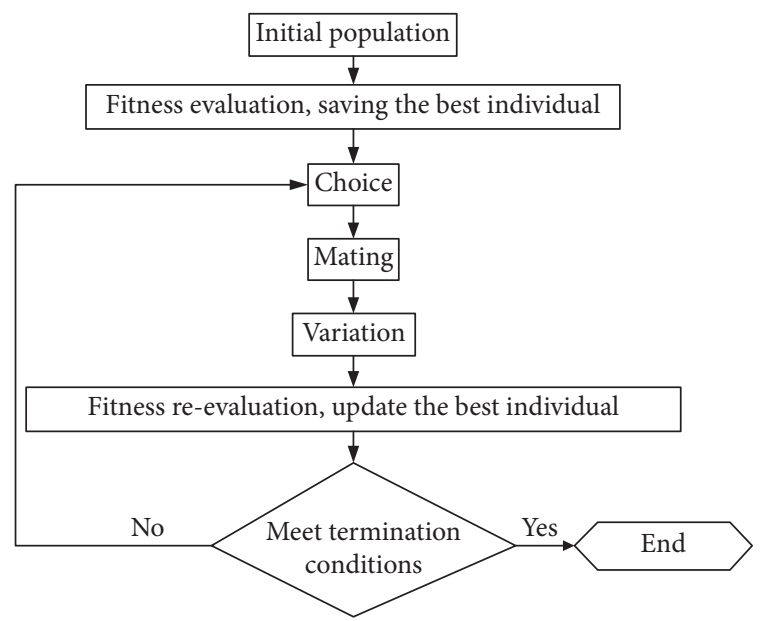

FIGURE 7: Flowchart of the genetic algorithm.

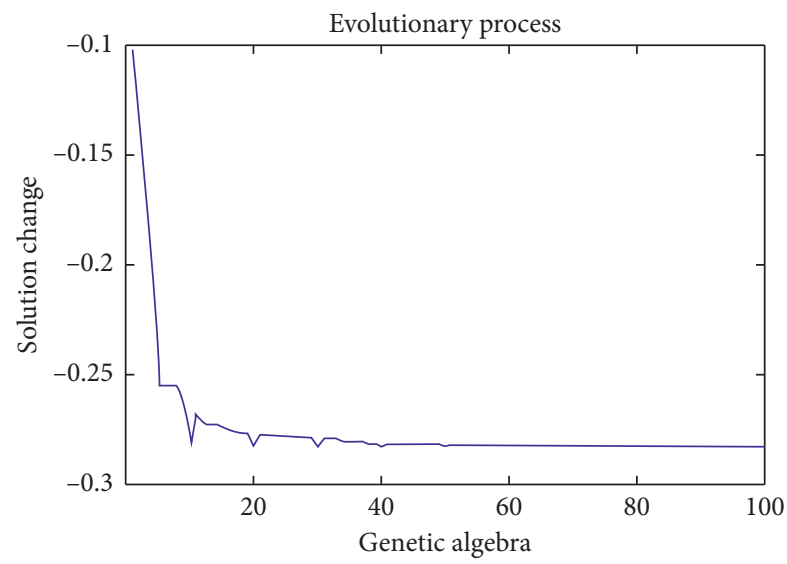

Figure 8: Iteration diagram of genetic algorithm.

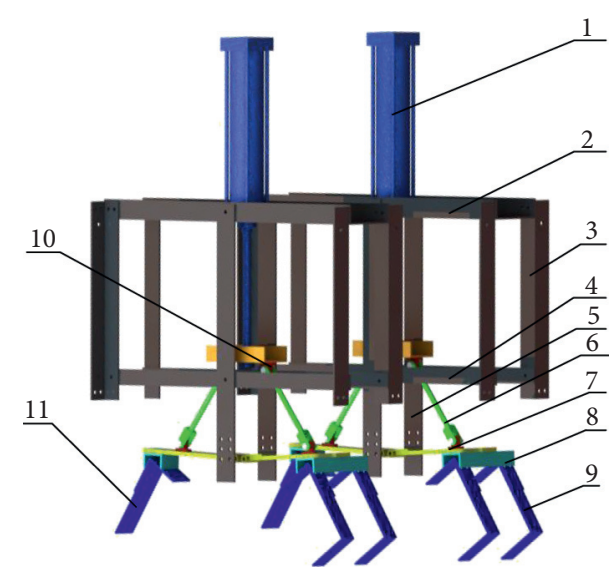

FIGURE 9: Manipulator structure.

and comparison. Hereinafter, those three manipulators were referred to as manipulators $\mathrm{A}, \mathrm{B}$, and $\mathrm{C}$, respectively.

3.2.1. Grasp Reliability and Accuracy Test. The rate and centering rates were two parameters used to determine the grasping reliability and accuracy. Samples were divided into

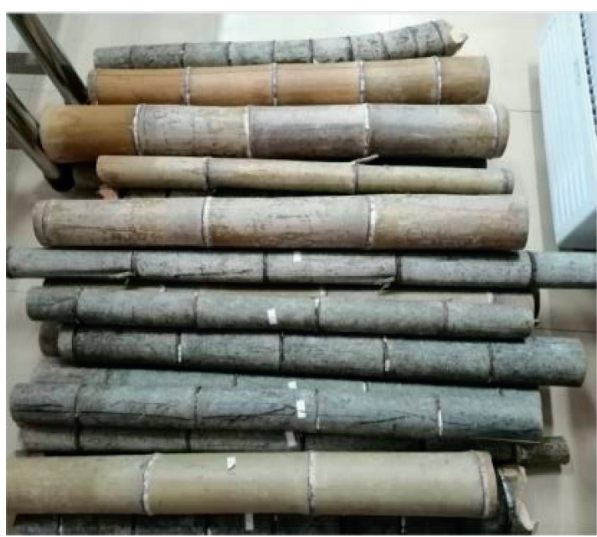

Figure 10: Experimental materials.

three gradients: $60-85,85-110$, and $110-135 \mathrm{~mm}$ according to diameter differences. If a sample was tightly captured between $\mathrm{V}$-shaped and $\mathrm{U}$-shaped fingers, the grasp was successful. Therefore, the capture rate was calculated by the number of successfully grasped samples divided by the total number of grasped samples.

If the distance between tool and sample centerlines was less than or equal to $5 \mathrm{~mm}$, the charging was accurate enough for useful production. Otherwise, the charging failed. Thus, the centering rate was computed by the number of successfully charged samples divided by the number of total charged samples. To estimate whether the charging was successful or not, a laser pointer was installed at the tool head center. At the end of every charging test, the distance between the laser light point and the center of the bamboo sample was measured using a caliper.

3.2.2. Dynamic Characteristic Test. To analyze the instantaneous movement of samples, a mercury series mer-030-120gx-pdes Poe Ethernet interface CCD was used to capture images of the grasping process. Its acquisition frequency was at 20 frames per second. Four images are shown in Figure 11, including before grasping (Figure 11(a)), a manipulator touching a sample (Figure 11(b)), a manipulator grasping a sample (Figure 11(c)), and after grasping was finished (Figure 11(d)).

A piezoelectric accelerometer (Chengke CT1010SLFP) was installed on manipulator wrist joint to detect its acceleration. The sampling frequency of the accelerometer was set as $1 \mathrm{kHz}$, and the measured voltages of acceleration signals, termed $V_{x}, V_{y}$, and $V_{z}$, were converted into $X, Y$, and $Z$ axis accelerations, termed $a_{x}, a_{y}$, and $a_{z}$, through a USB-6001 acquisition card, and input into a computer using USB 2.0 port (Figure 12).

An expression used to calculate the magnitude of the acceleration vector $a_{r}$ was obtained using (3), which was obtained in terms of its components $a_{x}, a_{y}$, and $a_{z}$, using the Pythagorean theorem.

$$
\left|a_{r}\right|=\sqrt{a_{x}^{2}+a_{y}^{2}+a_{z}^{2}},
$$




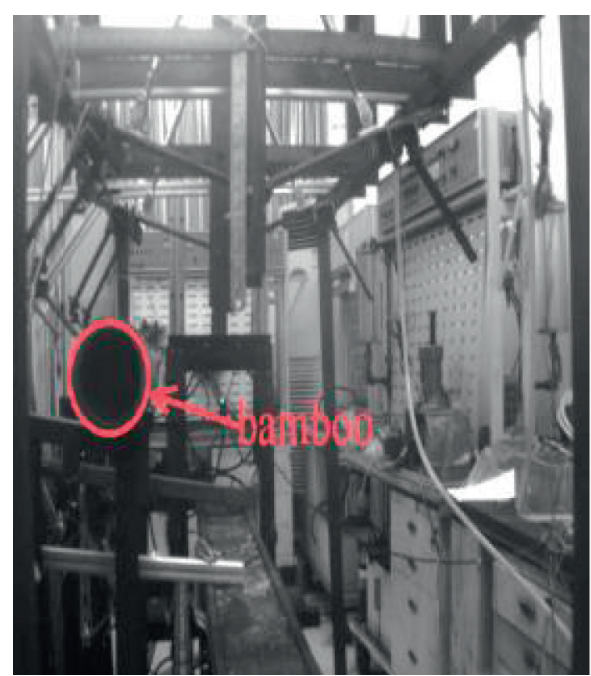

(a)

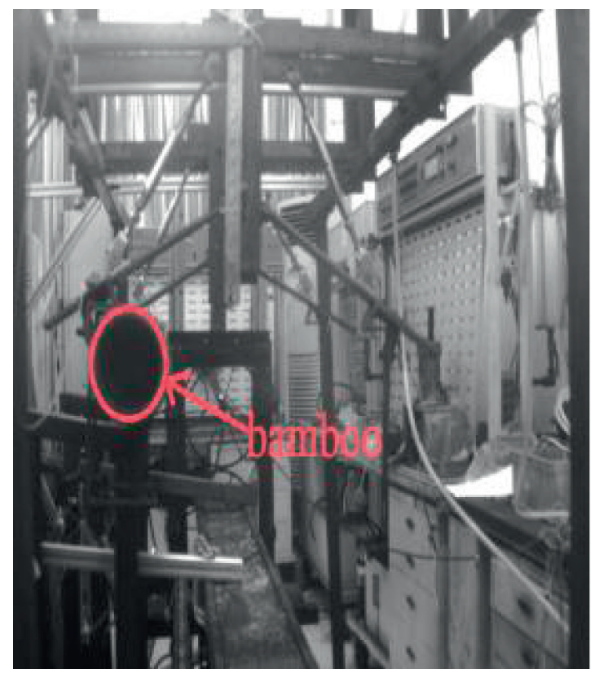

(c)

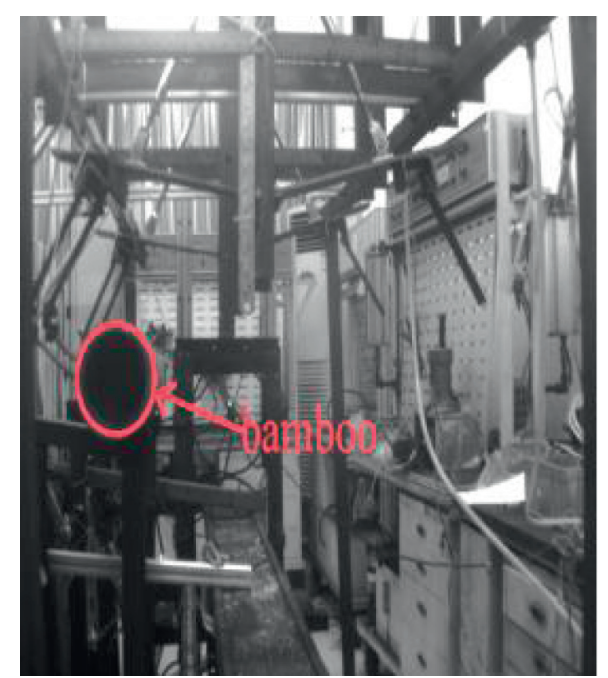

(b)

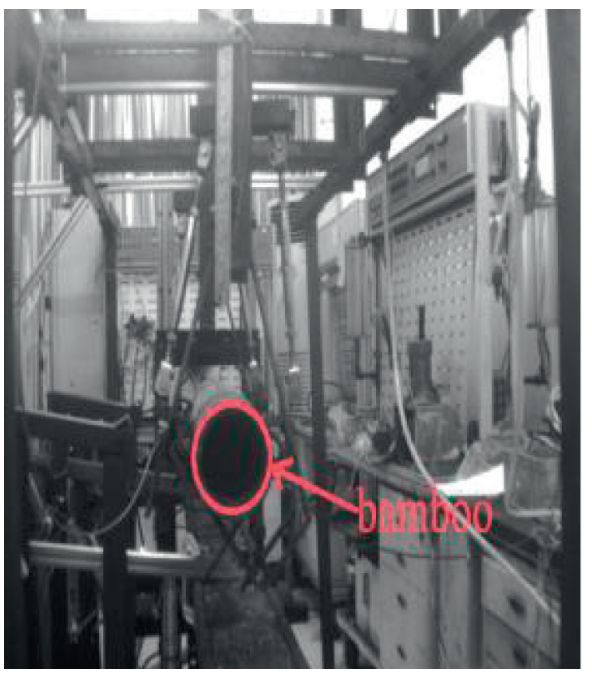

(d)

FIGURE 11: Four captured images in the grasping process.

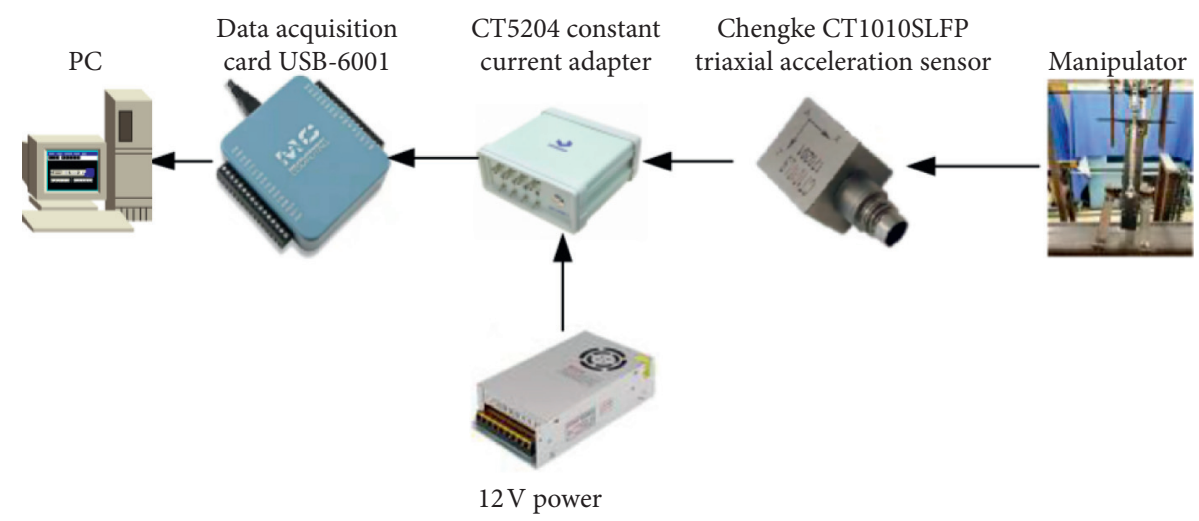

FIgURE 12: Accelerometer and signal conditioning system.

where $\left|a_{r}\right|$ is an absolute value or $\left|a_{r}\right| \geq 0$.

The average of the median of the resultant acceleration peaks and their standard deviation, which reflected the overall trend of acceleration more clearly, were used in result analyses and calculated using the following equation: 


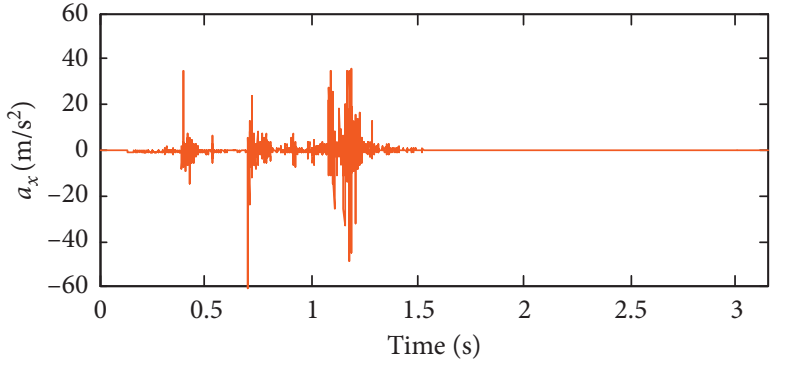

(a)

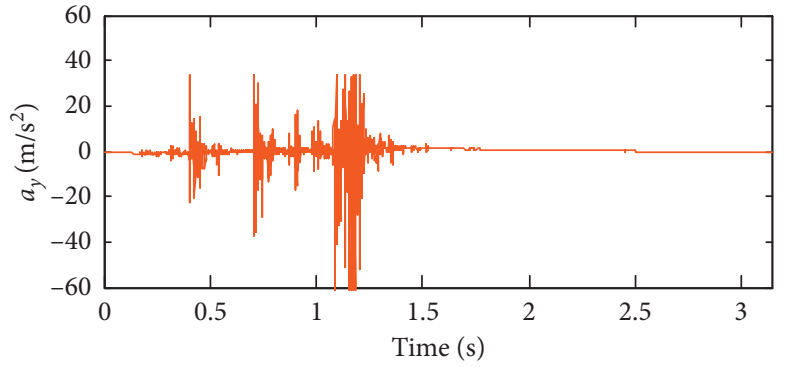

(b)

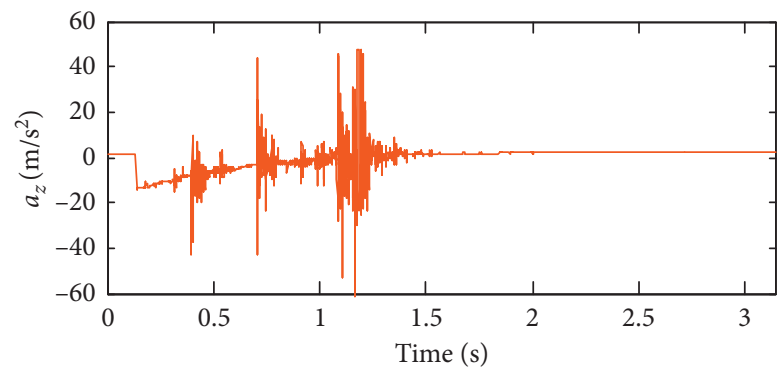

(c)

Figure 13: $X$ axis acceleration (a), $Y$ axis acceleration (b), and $Z$ axis acceleration (c).

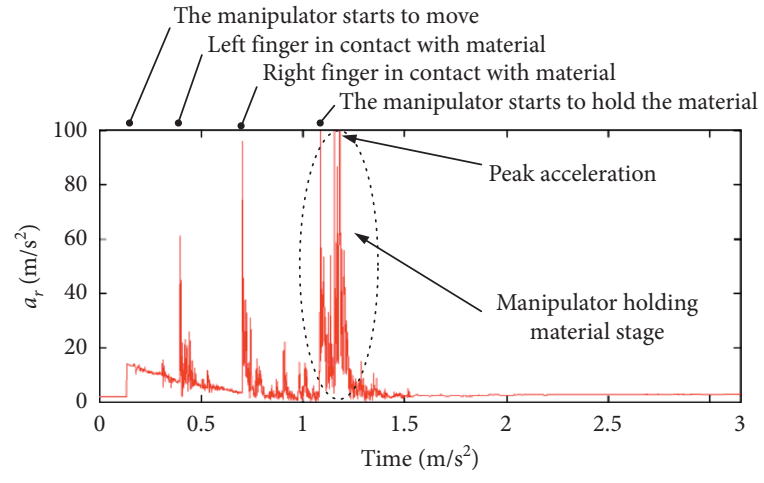

FIgURE 14: Magnitude of acceleration.

$$
\overline{\operatorname{Med}\left\{\left|a_{r}\right|\right\}}=\frac{1}{n} \sum_{i=1}^{n} \operatorname{Med}\left\{\left|a_{r}\right|\right\}_{i},
$$

where $\operatorname{Med}\left\{\left|a_{r}\right|\right\}_{i}$ represents the median of the resultant acceleration peaks for grasping the $i$ sample and $n$ represents the quantity of data in a group.

An example of $X, Y$, and $Z$ axis accelerations detected by the accelerometer is shown in Figure 13. The magnitude of acceleration vectors calculated from the accelerations in Figure 13 is shown in Figure 14. By analyzing the acceleration curve, the start and end time points of the grasp were found. Furthermore, the total period of grasp process was calculated using the following equation:

$$
t=\frac{n}{f}
$$

where $n$ is the sampled acceleration signal number from being a sample picked up to grasped firmly and $f$ is the sampling frequency of the accelerometer.

\begin{tabular}{|c|c|c|c|}
\hline Manipulator & $\begin{array}{c}\text { Diameter } \\
(\mathrm{mm})\end{array}$ & $\begin{array}{c}\text { Centering } \\
\text { rate } \\
(\%)\end{array}$ & $\begin{array}{c}\text { Capture } \\
\text { rate } \\
(\%)\end{array}$ \\
\hline \multirow{4}{*}{$A$} & $60-85$ & 87.50 & 92 \\
\hline & $85-110$ & 85.43 & 100 \\
\hline & $110-135$ & 89.64 & 96 \\
\hline & Average & 87.52 & 96 \\
\hline \multirow{4}{*}{$B$} & $60-85$ & 91.01 & 100 \\
\hline & $85-110$ & 87.76 & 100 \\
\hline & $110-135$ & 92.59 & 100 \\
\hline & Average & 90.45 & 100 \\
\hline \multirow{4}{*}{ C } & $60-85$ & 90.00 & 96 \\
\hline & $85-110$ & 86.34 & 100 \\
\hline & $110-135$ & 88.72 & 100 \\
\hline & Average & 88.35 & 98.67 \\
\hline
\end{tabular}

TABLE 1: Test results.

\section{Results and Discussion}

\subsection{Results}

4.1.1. Grasp Reliability and Accuracy Test. Experimental results for the capture and centering rates of manipulators $A$, $B$, and $C$ are shown in Table 1 . The average capture rate of manipulators $A, B$, and $C$ were 96,100 , and $98.67 \%$, and their centering rates were at $87.52,90.45$, and $88.35 \%$, respectively. In general, the average capture rate for grasping samples of $85-110 \mathrm{~mm}$ diameter was the highest and that for grasping samples of $60-85 \mathrm{~mm}$ diameter was the lowest. There results also demonstrated that the capture rate of manipulator B was as high as $100 \%$, and therefore manipulator B was the most suitable for this intelligent bamboosplitting machine. The average centering rate of this experiment was $<91 \%$. The captured images showed that the 


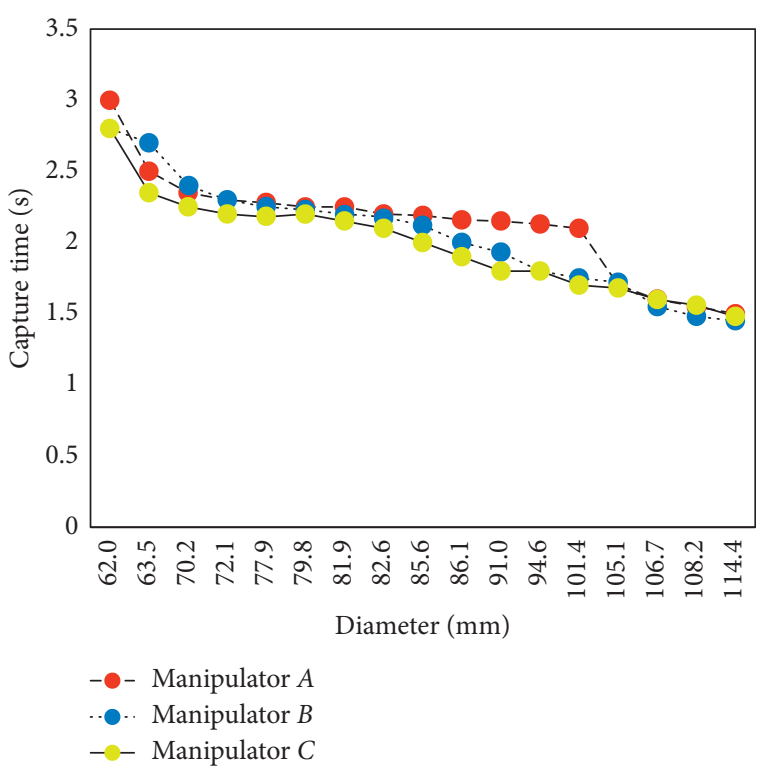

FIGURE 15: Capture time of grasping diameter.

cause of the centering error was that some sample sections were not circular.

4.1.2. Dynamic Characteristic Test. Capture time curves of manipulators $A, B$, and $C$ are in shown in Figure 15, which demonstrated that capture time decreased with sample diameter. No significant capture time differences were observed among these three manipulators in grasping samples with diameters between 105.1 and $114.4 \mathrm{~mm}$. The trend curves of the influence of sample diameter on average capture time were similar to exponential curves; the fitted curve expressions are listed in Table 2.

No matter which manipulator was used for grasping, the average acceleration decreased with decreased sample diameter (Figure 16). The longer the big arm was, the greater the average acceleration became. The trend curves of the influence of the sample diameter on the average acceleration were also similar to exponential curves; the fitted curve expressions are listed in Table 3.

4.2. Discussion. The longer the big arm was, the larger the grasping force of the manipulator was, and the faster the grasping speed was. Captured images showed that in grasping with manipulator $C$, small samples always slipped in the groove of U-shaped fingers acting at high speed, and some samples stuck between $U$ and V-shaped fingers at wrong positions. Thus, the capture rate of manipulator $C$ grasping samples of diameters between 60 and $85 \mathrm{~mm}$ was only $96 \%$. If the big arm was too short, the grasping force became too small to grasp small materials, which also explained why the average centering rate of manipulator $A$ was the lowest.

When picked up by U-shaped fingers, big samples can barely slide, being captured firmly and quickly. Therefore,
TABle 2: Capture time formula.

\begin{tabular}{lcc}
\hline Manipulator & Capture time formula & $R^{2}$ \\
\hline$A$ & $t=2.8144 e^{-0.033 d}$ & 0.8284 \\
$B$ & $t=2.8384 e^{-0.038 d}$ & 0.9665 \\
$C$ & $t=2.6327 e^{-0.033 d}$ & 0.9535 \\
\hline
\end{tabular}
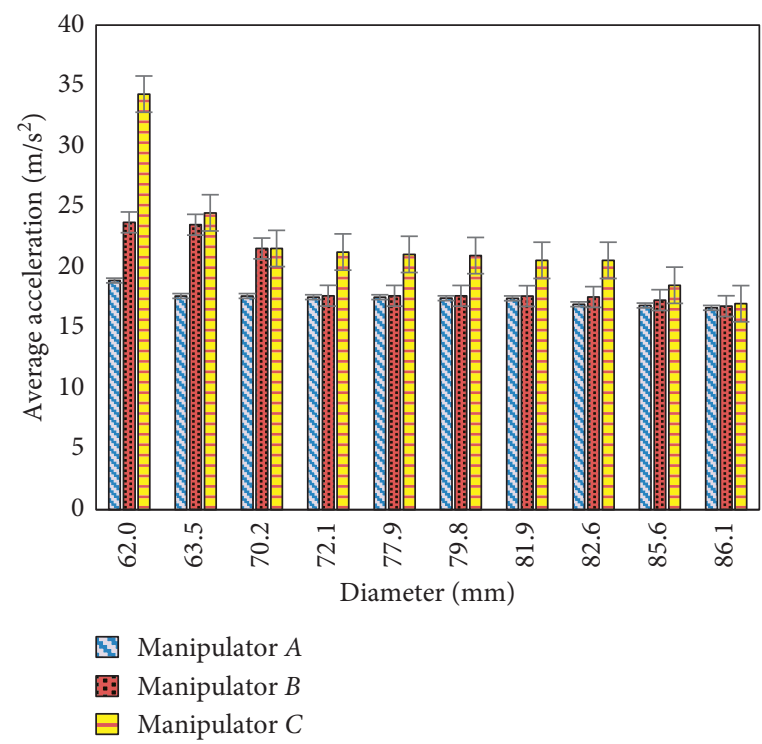

FIGURE 16: Average acceleration of grasping.

TABle 3: Average acceleration formula of grasping.

\begin{tabular}{lcc}
\hline Manipulator & Average acceleration formula & $R^{2}$ \\
\hline$A$ & $a=18.65 d^{-0.044}$ & 0.8491 \\
$B$ & $a=24.472 d^{-0.17}$ & 0.8549 \\
$C$ & $a=31.05 d^{-0.239}$ & 0.8676 \\
\hline
\end{tabular}

the required time for grasping big samples was shorter. If the big arm was too short, the grasping force became insufficient and materials vibrated in U-shaped fingers with a large amplitude. This explained why the required time for manipulator A for capturing samples was the longest.

The captured images showed that small samples vibrated violently in U-shaped fingers. Due to the size limitation of U-shaped fingers, the vibration space of large samples was limited. As the big arm became longer, the grasping force became larger and the instantaneous grasping acceleration became larger. This explained why the detected average acceleration of manipulator $C$ was the highest.

\section{Conclusions}

Experiment results showed that the average capture rate of manipulator $B$ was $100 \%$, and its average centering rate was $90.45 \%$. Therefore, it grasped samples with different diameters successfully. The size of manipulator $B$ was also equal to our calculated optimal size. These 
experiments partly validated the present optimization strategy.

The required time for grasping larger samples was shorter than that of grasping smaller samples. The trend curves of the influence of sample diameter on average grasping time were similar to exponential curves, and the fitted curve expression of manipulator $B$ was $t=2.8384 e^{-0.038 d}$. The trend curves of sample diameter influence on the average acceleration were also similar to exponential curves, and the fitted curve expression of manipulator $B$ was $a=24.472 d^{-0.17}$.

\section{Data Availability}

The processed data required to reproduce these findings cannot be shared at this time as the data also form part of an ongoing study.

\section{Conflicts of Interest}

The authors declare that they have no conflicts of interest.

\section{Acknowledgments}

This research was co-supported by the National key Research and Development Program of China (project approval no. 2018YFD0101001) and Guangdong Science and Technology Plan Projects (grant nos. 2017A010102024 and 2017A020208052).

\section{References}

[1] J. M. Xu, R. J. Zhao, and B. H. Fei, "Research on properties and utilization of bamboo in China," Wood Processing Machinery, vol. 18, no. 3, pp. 39-42, 2007, in Chinese.

[2] G. H. Gao, Z. Y. Dong, X. N. Sun, and H. Wang, "Development and test of a flexible manipulator based on 3D printing," Smart Agriculture, vol. 1, no. 1, pp. 85-95, 2019, in Chinese.

[3] Y. W. Zhao, D. X. Geng, X. M. Liu, and G. D. Sun, "Kinematics and experiment on pneumatic flexible fruit and vegetable picking manipulator," Transactions of the Chinese Society for Agricultural Machinery, vol. 50, no. 08, pp. 31-42, 2019, in Chinese.

[4] Y. K. Peng, Y. Ma, and L. Li, "Design and experiment of apple internal quality sorting manipulator," Transactions of the Chinese Society for Agricultural Machinery, vol. 50, no. 1, pp. 307-312, 2019, in Chinese.

[5] B. Li, S. Gu, L. Chu et al., "Design and experiment on manipulator for transplanting leaf vegetables seedling cultivated by coco-peat," Transactions of the Chinese Society of Agricultural Engineering, vol. 33, no. 14, pp. 18-24, 2017, in Chinese.

[6] X.-J. Wan, Q. Li, and K. Wang, "Dimensional synthesis of a robotized cell of support fixture," Robotics and ComputerIntegrated Manufacturing, vol. 48, pp. 80-92, 2017.

[7] G. Coppola, D. Zhang, and K. Liu, "A 6-DOF reconfigurable hybrid parallel manipulator," Robotics and Computer-Integrated Manufacturing, vol. 30, no. 2, pp. 99-106, 2014.

[8] J. S. Mandur and H. M. Budman, "Simultaneous model identification and optimization in presence of model-plant mismatch," Chemical Engineering Science, vol. 129, pp. 106-115, 2015.

[9] J. S. Mandur and H. M. Budman, "Robust algorithms for simultaneous model identification and optimization in the presence of model-plant mismatch," Industrial \& Engineering Chemistry Research, vol. 54, no. 38, pp. 9382-9393, 2015.

[10] Y. Okazaki, M. Yamamoto, M. Komatsu, Y. Tsusaka, and Y. Adachi, "Development of a human safe, multi-degree-offreedom robot arm Technology using pneumatic muscles," Journal of the Robotics Society of Japan, vol. 28, no. 3, pp. 302-310, 2010.

[11] J. He, F. Gao, S. Wu, R. Liu, and X. Zhao, "Measure dimension of rotating large hot steel shell using pulse laser on PRRR robot," Measurement, vol. 45, no. 7, pp. 1814-1823, 2012.

[12] A. Abe, "Trajectory planning for residual vibration suppression of a two-link rigid-flexible manipulator considering large deformation," Mechanism and Machine Theory, vol. 44, no. 9, pp. 1627-1639, 2009.

[13] M. Benosman, G. L. Vey, L. Lanari, and A. De Luca, "Rest-torest motion for planar multi-link flexible manipulator through backward recursion," IFAC Proceedings, vol. 36, no. 17, pp. 289-294, 2003.

[14] B. Tondu, S. Ippolito, J. Guiochet, and A. Daidie, "A sevendegrees-of-freedom robot-arm driven by pneumatic artificial muscles for humanoid robots," The International Journal of Robotics Research, vol. 24, no. 4, pp. 257-274, 2005.

[15] M. A. Ahmad, R. R. Ismail, M. Ramli, M. A. Zawawi, and M. H. Suid, "Vibration control strategy for flexible joint manipulator: a fuzzy logic control approach industrial electronics \& applications (ISIEA)," in Proceedings of the Symposium on Industrial Electronics and Applications (ISIEA), pp. 469-474, IEEE, Penang, Malaysia, October 2010.

[16] P. Nikdel, M. Hosseinpour, M. A. Badamchizadeh, and M. A. Akbari, "Improved takagi-sugeno fuzzy model-based control of flexible joint robot via hybrid-taguchi genetic algorithm," Engineering Applications of Artificial Intelligence, vol. 33, no. 8, pp. 12-20, 2014.

[17] Y. Li and Q. Xu, "GA-based multi-objective optimal design of a planar 3-dof cable-driven parallel manipulator," in Proceedings of the International Conference on Robotics and Biomimetics, pp. 1360-1365, IEEE, Kunming, China, December 2006.

[18] Z. Gao, D. Zhang, and Y. Ge, "Design optimization of a spatial six degree-of-freedom parallel manipulator based on artificial intelligence approaches," Robotics and Computer-Integrated Manufacturing, vol. 26, no. 2, pp. 180-189, 2010.

[19] H. Kojima and T. Kibe, "Optimal trajectory planning of a twolink flexible robot arm based on genetic algorithm for residual vibration reduction," in Proceedings of the: IEEE International Conference on Intelligent Robots and Systems (IROS), November 2001.

[20] G. Chen, H. Wang, and Z. Lin, "Determination of the identifiable parameters in robot calibration based on the POE formula," IEEE Transactions on Robotics, vol. 30, no. 5, pp. 1066-1077, 2014.

[21] A. Klimchik, D. Bondarenko, A. Pashkevich, S. Briot, and B. Furet, "Compliance error compensation in robotic-based milling informatics," in Control, Automation and Robotics, pp. 197-216, Springer, Cham, Switzerland, 2014.

[22] H. N. Rahimi and M. Nazemizadeh, "Dynamic analysis and intelligent control techniques for flexible manipulators: a review," Advanced Robotics, vol. 28, no. 2, pp. 63-76, 2014.

[23] T.-H. Liu, R. Ehsani, A. Toudeshki, X.-J. Zou, and H.-J. Wang, "Detection of citrus fruit and tree trunks in natural environments using a multi-elliptical boundary model," Computers in Industry, vol. 99, pp. 9-16, 2018. 
[24] T.-H. Liu, R. Ehsani, A. Toudeshki, X.-J. Zou, and H.-J. Wang, "Identifying immature and mature pomelo fruits in trees by elliptical model fitting in the $\mathrm{Cr}-\mathrm{Cb}$ color space," Precision Agriculture, vol. 20, no. 1, pp. 138-156, 2019.

[25] M. Bucolo, A. Buscarino, C. Famoso, L. Fortuna, and M. Frasca, "Smart control of imperfect electromechanical systems," in Proceedings of the 2019 IEEE International Conference on Systems, Man and Cybernetics (SMC), pp. 1882-1886, IEEE, Bari, Italy, October 2019.

[26] M. Bucolo, A. Buscarino, C. Famoso, L. Fortuna, and M. Frasca, "Control of imperfect dynamical systems," Nonlinear Dynamics, vol. 98, no. 4, pp. 2989-2999, 2019. 